\title{
Orthodontic workforce for the next 10 years
}

\author{
Dr. Dashrath Kafle,
} Chief Editor

Orthodontic and Dentofacial Orthopedic Association of Nepal (ODOAN) was established in 2007 A.D after reaching minimum required number of orthodontists eligible to open an association by law. Until that time only seven orthodontists were present in Nepal and they are the founding members of ODOAN. This number somehow remained constant for the coming few years. In the last decade the number of orthodontists in Nepal has increased many folds. Approximately 150 orthodontists are registered with the Nepal Medical Council currently. This increase in number is mainly because of the availability of postgraduate education in Nepal and more opportunities in abroad as well. Orthodontists comprise the highest number of dental specialists registered with the NMC. At present, around 18 postgraduate seats are allocated every year for orthodontics in Nepalese insititutions alone. This number is going to further increase in future because more number of orthodontic faculties will be eligible to take postgraduate students.

Now the debate is: are we overproducing orthodontists? Should we stop producing orthodontists? Are the orthodontists becoming jobless? Are there fewer opportunities for the orthodontists? To answer these questions we need to have a sneak peek into some of the facts and figures from developed countries, and developing countries similar to Nepal. Let's take example of developed countries first where healthcare system is on top priority of the government, insurance system is strong and most of the population has access to oral health care including orthodontics. According to the $\mathrm{AAO}$, the number of orthodontists in the USA is $11520 .{ }^{1,2}$ Similarly, the number of orthodontists in Australia, Germany and Canada are 552, 3000 and 799 respectively. ${ }^{4}$ The number will remain mere number unless we find orthodontists and population ratio. Looking at the population and number of orthodontist, USA and Germany seem to have highest number of orthodontists for the population which is 1: 30865 and 1:27883 respectively. Canada and Australia have Orthodontists and population ratio in the range of approximately 1:47000. Looking at the figure in developing countries, India is the second most populous country in the world where the number of orthodontists registered with the Indian orthodontic Society is $5000 .{ }^{5}$ Similarly, Bangladesh has approximately 200 orthodontists and Sri Lanka has only 59 orthodontists. ${ }^{5}$ With these numbers, orthodontist to population ratio is $187000-968000$ in most of the developing countries. When we compare the data from developing countries, the number of orthodontists is more in Nepal as compared to India, Bangladesh and Sri Lanka. The number of orthodontic post-graduate seats is in increasing trend which means that in coming ten years orthodontists to population ratio is going to increase in Nepal. However, the job opportunities and academic positions are not increasing in a similar manner which is the biggest challenge for budding orthodontists. In the next 10 years, with the current growth trend of orthodontic post graduate seats, it will not be surprising to have 500 orthodontists in Nepal. This number itself is not big compared to developed countries but in a country like Nepal, where most of the population reside in rural districts, the accessibility to orthodontic service is mainly confined to major urban areas. So without proper planning on how to engage/ utilize these manpower, it will be wiser to scientifically do the need assessment before increasing the number of graduates. In the meantime the government should strongly plan to recruit orthodontists in district level hospitals. Dental schools and Universities should plan to recruit more orthodontists to engage in clinical, academic and research arena.

\section{OJN}

\section{REFERENCES}

1. https://www.aaoinfo.org

2. https://www.ibisworld.com/industry-statistics/market-size/orthodontists-united-states/

3. https://www.aihw.gov.au/reports/dental-oral-health/oral-health-and-dental-care-in-australia/contents/dental-workforce

4. Tanne K. Current status of dental and orthodontic education in European and American countries. APOS Trends in Orthodontics; 9.

5. Personal communication to society presidents. 